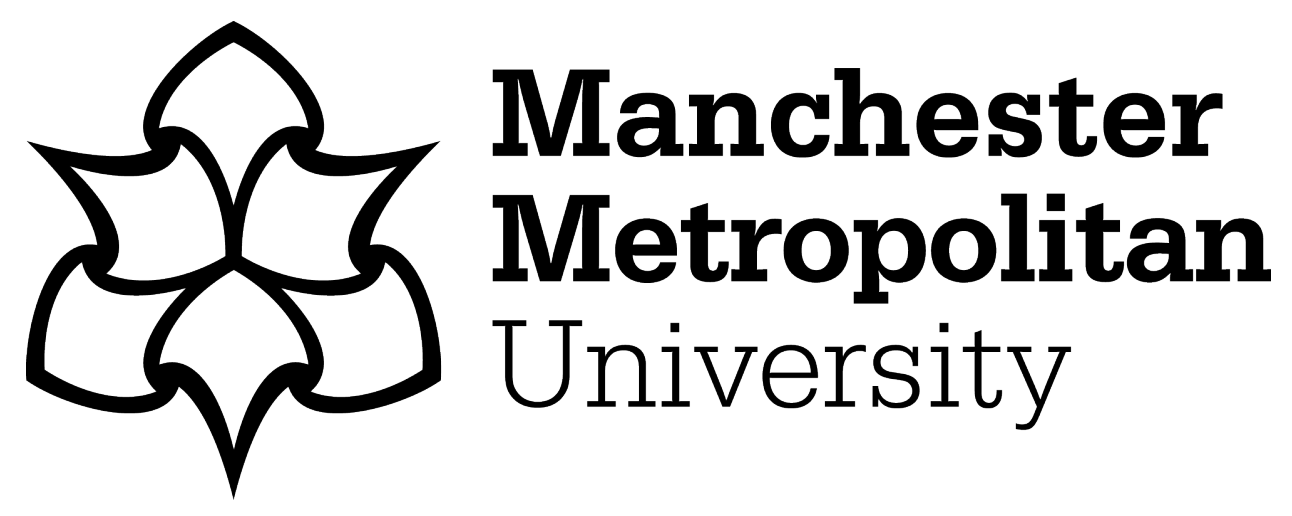

Turley, EL, King, N and Monro, S (2018) 'You want to be swept up in it all': Illuminating the erotic in BDSM. Psychology and Sexuality, 9 (2). pp. 148160. ISSN 1941-9899

Downloaded from: https://e-space.mmu.ac.uk/620056/

Version: Accepted Version

Publisher: Taylor \& Francis (Routledge)

DOI: https://doi.org/10.1080/19419899.2018.1448297

Please cite the published version 


\title{
'You want to be swept up in it all': Illuminating the erotic in BDSM
}

\author{
Abstract \\ This research aims to understand the eroticism of consensual bondage, discipline, dominance \& submission and \\ sadism \& masochism (BDSM). Eroticism is considered a central feature of most sexual experiences, yet there is \\ limited research that examines erotic components of BDSM as lived by practitioners themselves. By adopting an \\ experiential approach to the study using phenomenological psychology, the lived experiences of BDSM \\ practitioners were foregrounded in order to clarify erotic meanings and extend existing understandings of \\ consensual BDSM.
}

Nine frequent practitioners of consensual BDSM were interviewed; discussing specific accounts of their BDSM experiences. Template analysis was utilised to analyse data, within an interpretive phenomenological framework. Findings illustrated that one of the most important erotic aspects was the co-collaboration between practitioners in order to create, maintain and engage with the erotic fantasy. The unpacking of the complexity of eroticised power exchange that occurred when BDSM practitioners adopted their sexual roles was also an important finding to emerge from the analysis.

Keywords

BDSM, sexual fantasy, eroticism, phenomenology, template analysis, qualitative research

\section{Introduction}

Consensual bondage, discipline, dominance \& submission and sadism \& masochism, generally referred to as BDSM, is an area of growing interest to psychology. However, there has been limited empirical research specifically investigating the lived erotic experience of participating in consensual BDSM. Although there is no generally accepted definition of BDSM, here the term is used to describe a set of consensual sexual and erotic sexual practices that usually involve the application or receipt of intense physical and/or emotional sensations (Turley \& Butt, 2015), and an eroticised exchange of power (Langdridge \& Butt, 
2005). The acronym 'BDSM' illustrates the assorted consensual activities involved in the experience of participating in BDSM; bondage and discipline (B\&D), dominance and submission (D/s), and sadism and masochism (SM). Practitioners and authors also often use the abbreviations S/M, EPE (erotic power exchange) or WIITWD (what it is that we do) to describe and discuss the same range of sexual practices and activities.

The term BDSM is commonly used and accepted amongst practitioners, and is the term that will be used throughout this paper. It is a common misconception that BDSM play always must include some sort of pain, yet this is not necessarily the case, however, there should be some psychological power exchange involved in the scene, and interestingly, BDSM does not always have to include sexual contact (Turley, 2018, in press). The range of BDSM activities are diverse, and depends on the fantasies of those involved (for a detailed explanation of BDSM activities see Turley \& Butt, 2015). The range of BDSM activities are subtle and complex, and this paper aims to elucidate some of that complexity in order to gain insight into the lived experience of participating in consensual BDSM, especially exploring the erotic meanings for those who participate.

Studies estimating the frequency of individuals with BDSM-related interests have indicated that BDSM practice is not particularly rare, ranging from $10 \%-22 \%$ of the population (Kinsey, Pomeroy, Martin \& Gebhard, 1953, Moser \& Kleinplatz, 2006, Richters, de Visser, Rissel, Gulrich \& Smith, 2008). In terms of demographics, studies have suggested that BDSM practitioners tend to be white, well educated, and have higher than average annual incomes, and that they began participating in BDSM during young adulthood (Sandnabba, Santtila \& Nordling, 1999, Moser \& Kleinplatz, 2006).

There has been steady growth in the range and scope of empirical research in this area. However, much of the research on consensual BDSM has tended to concentrate on more peripheral issues, such as seeking to catalogue sexual practices, identify characteristics of 
practitioners, and examine the views and attitudes of others towards BDSM practitioners. There has however, been surprisingly little work that seeks to focus on eroticism itself as it is experienced by those who engage in, it and the meanings they accord to it. Interestingly, Turley, King and Butt (2011) in a study of the social world of BDSM reported that descriptions of the eroticism involved in these acts were largely absent from BDSM practitioner's own accounts; instead participants usually fell back on popular lay-scientific discourses rather than discuss their own experiences and understandings.

Exploring the eroticism of BDSM from an experiential perspective, by taking a phenomenological approach to the work, enables the production of a rich and detailed understanding of the erotic nature and potential of this phenomenon. The aim of the phenomenological approach is to illuminate phenomena through how they are perceived by the individuals in a situation, in this case eroticism within BDSM scenes, while focusing on the wholeness of experience rather than breaking it down into separate parts (Moustakas, 1994). Unlike other qualitative methods, experiential research places the centrality of 'being' as fundamental to understanding the nature of experiences of a particular phenomenon (Spinelli, 2005). Phenomenological approaches are grounded in a paradigm of personal experience and subjectivity, and emphasise the importance of personal perspective and interpretation, and thus they are valuable for understanding subjective experiences of phenomena (Moustakas, 1994). It recognises that the 'sexual' and the 'erotic' can hold a variety of different meanings, and though there may be an overlap, the two concepts are not mutually exclusive. 'The erotic' in this case is understood to hold a broader and greater diversity of meanings than 'the sexual', and encompass a wider range of concepts including a sense of atmosphere and particularly nuanced desires, and a move away from genitally centric descriptions. The complexity of BDSM means it can be experienced on many levels, 
therefore a study of the erotic experience of the phenomenon will likely offer more valuable findings than a study of the sexual experience of BDSM.

As mentioned, much of the existing research has tended to focus on aspects of BDSM, other than on the erotic nature of the practice. Topics covered include; BDSM associated practices (Nordling, Sandnabba, Santtila \& Alison, 2006), the characteristics of those who practice BDSM (Richters, de Visser, Rissel, Gulrich and Smith, 2008, Wismeijer and van Assen, 2013), and the views and attitudes of others about BDSM practitioners (Yost, 2009).

Nevertheless, research investigating the sexual acts and practises associated with BDSM has been successful in teasing apart the different meanings involved in these acts, and the range and variety of behaviours encompassed (Alison, Santtila, Sandnabba \& Nordling, 2001; Tomassilli, Golub, Bimbi \& Parsons, 2009). Kleinplatz and Moser (2007) developed a useful taxonomy that recognised the subtle differences in behaviour that exist beneath the broad practice headings. They examined roles, commonalities, bondage, discipline, dominance, submission, symbols, physical pain, humiliation, fetishes and relationships. It is important to acknowledge that creating a comprehensive taxonomy is difficult due to the highlighted issues of nuanced distinctions between and within sexual practices. In addition, by categorising practices and activities, there is a risk of excluding, and therefore 'othering', individuals and activities that do not conform to the categories outlined.

Frequently BDSM practitioners are located in the contemporary academic and popular literature that positions them as pathological, deviant or abnormal, although there is little empirical evidence to support this claim. It is also the case that the Diagnostic and Statistical Manual of Mental Disorders (DSM) has a tradition of pathologising BDSM practitioners and consensual practices, despite the lack of supporting evidence for conceptualisation as pathology. Willig (2008) suggests that 'risky' sexual practices, such as BDSM, are often 
perceived as manifestations of pathologies or damage within an individual because 'normal' individuals would not behave in a manner that risked their health. However, that far from being deviant, there exist various and diverse rationalities behind engaging in the behaviours, and a range of studies concluded that those who practice consensual BDSM are no more or less dangerous or psychologically damaged than those who not participate in BDSM (Denman, 2004; Connolly, 2006; Wismeijer \& van Assen 2013).

The attitudes and views of individuals who do not participate in BDSM are found to be negative towards BDSM enthusiasts (Stockwell, Walker \& Eshleman, 2010). Researchers argue that this mainly arises because of the pathologisiation of BDSM by the mainstream media (Yost, 2009; Wilkinson, 2009). Yost (2009) reported that participants who had prior knowledge of BDSM via their own involvement, the involvement of others or simply via a higher level of awareness, displayed more positive attitudes towards BDSM. Negative attitudes towards BDSM practitioners appear to stem from misunderstandings about the sexual practice, many of which are misinformed by the media (Weiss, 2006).

Recent research has conceptualised consensual BDSM in a variety of different ways. Turley (2016) theorised that BDSM can be interpreted as a method of embodied exploration; that engaging in BDSM, either as the dominant/top or submissive/bottom partner, enables enhanced feelings of corporeality and exploration of bodily relationships with the world and with other people. BDSM has also been conceptualised as a type of adult play, with its own rules and boundaries, and with erotic signifiers to provide the contextual framework for the play (Harviainen, 2011; Faccio, Casini \& Cipoletta, 2014; Turley, Monro \& King, 2017). Although this research is useful to increase understandings of BDSM, the central feature of BDSM for many practitioners lies in the erotic nature of the practices (Langdridge and Barker, 2007). Although limited, existing qualitative research has examined BDSM and eroticism focusing on fantasy, ritual, roles and consumerism (Rubin, 2005; Weiss, 2011; 
Lindemann, 2012), and has provided some useful insights into the phenomenon. The current work differs however, due to the methodological perspective that foregrounds lived experiences and uses phenomenological psychology to approach to the research. This paper presents an experiential study of BDSM, investigating how eroticism is experienced as lived during the BDSM scene, can make a real contribution to extending our understandings.

\section{The current study}

Turley et al. (2011), examining the social world of BDSM made the point that participant descriptions of BDSM largely neglected the eroticism that they experienced. Those aspects of BDSM play that are viscerally erotic were missing from their findings, which posed the question 'where is the eroticism to be found in BDSM?' The research presented here was designed to address this issue by focusing specifically on gaining understanding of the erotic nature of BDSM through the application of phenomenological methods, and the ways this is experienced by practitioners during their BDSM encounters.

\section{Method}

\section{Phenomenology}

The phenomenological method is an inductive, richly descriptive research method with the purpose of describing the nature of experience as it appears to experiencers (Giorgi, 1997). The aim of phenomenological research is to explore the lived experience of a specific phenomenon from the perspective of those who experience that particular phenomenon; in this case, individuals who practice consensual BDSM. The choice of data collection method in phenomenology is selected by its capacity to elucidate participants' experiences of phenomena in the form of rich, descriptive accounts which can then be analysed in the selected phenomenological tradition; in this case interpretive phenomenology (see Langdridge, 2007; Turley, 2016, for additional detail on interpretive phenomenology). 


\section{Design}

Ethical approval for this study was granted by the University of Huddersfield ethics committee. Recruitment of participants was via a combination of a purposive and snowball sampling strategies, and nine people based in the UK participated in the research. The purposive element to the sampling was in order to ensure variation in terms of BDSM role, sexuality, sex and age, while the snowball aspect was an attempt to circumvent the difficulties associated with 'outsider' researchers gaining access to 'hidden' populations (Ellard-Gray, Jeffrey, Choubak and Crann, 2015). The study was advertised via word of mouth by a prominent member of the BDSM community to recruit initial participants. This initial group then suggested the study to others within their social circles, and interested individuals contacted the first author to volunteer to participate. The inclusion criteria for this study were that participants should have been involved in regular, consensual BDSM for the purpose of sexual pleasure (rather than, for example, financial gain) for at least six months and have engaged in recent BDSM experiences. The sample consisted of four men and five women, ranging in age from twenty-six to forty-eight years old, each defined their role in BDSM as top/dominant, bottom/sub/submissive or switch (where the individual switches between the role of top and bottom). Participants' sexualities were diverse, and the sample included heterosexual, gay, bisexual and pansexual individuals. All participants worked in professional job roles, with the exception of two; one was a student and the other chose not to work. Data were in the form of participants' written accounts followed by semi-structured interviews. Participants were initially asked to produce two descriptive, context-rich, narrative accounts of their BDSM experiences; one illustrating a good experience, and the other describing an experience that was unsatisfying or unpleasant. Participant instructions requested the experiences should be within the last year, each around a side of A4 paper in 
length and were to be emailed to the first author four days before the interview was scheduled to take place. An interview schedule with a focus on the differences in feelings of eroticism between the two accounts was then designed specifically for each participant based on the good and bad examples provided, with the aim of elucidating the erotic constituents of the experience of BDSM participation. The interviews and subsequent data analysis were completed by the first author.

\section{Template analysis}

Template analysis is a style of thematic analysis that involves the development and refinement of themes through the application of a hierarchical coding template (King, 2012). This analytic method is more flexible than other thematic methods, enabling a tailored approach to analysis (see Brooks, McCluskey, Turley \& King, 2015). Template analysis does not prescribe a specific number of coding or hierarchical levels, enabling a more detailed development of the template where necessary to reflect depth and complexity in the data and consequently the analysis.

Template analysis also allows the use of pre-selected themes, known as a priori themes, which are used to identify themes that are likely to be relevant to the analysis (King, 2012). The starting point of the current analysis was the selection of a priori themes that emerged from earlier work; authenticity, anticipation, BDSM relationships and the use of fantasy (Turley, King, \& Butt, 2011). It is from this initial engagement with the data that the coding structure is developed. As is usual in template analysis, a subset of the interview transcripts, along with the a priori themes were used to formulate the initial template. The initial template consisted of three top level themes, and the first author maintained a sensitivity to these thematic areas, while also continuing with the open phenomenological attitude required for the work. The first author used the phenomenological techniques of bracketing and continued 
critical self- reflection throughout the analysis in order to recognise her presuppositions about the phenomena under investigation, and foreground the participants' own experiences as lived.

The initial template was used to code each interview transcript, and this template developed to incorporate new themes and subthemes as the coding progressed. With each change made to the template, the previous coding was adjusted to include this. Through various modifications, a final version of the template was produced consisting of six top level themes and associated subthemes (see Brooks, McCluskey, Turley \& King, 2015, for additional information regarding the templates used in the current analysis).

\section{Findings}

The analysis of the data obtained produced a rich and complex picture of the participants' experiences of eroticism in BDSM, and its wider context. Within this paper, we will focus on the two main themes that most directly illuminate the issue of what it is that is erotic in BDSM: eroticism in power exchange, and co-creating erotic fantasy in the BDSM experience (see Brooks, McCluskey, Turley \& King, 2015, for additional information regarding how the themes were developed from the templates). In future papers we intend to examine some of the other findings originating from this research. Names used in this section are pseudonyms.

\section{Eroticism in power exchange}

Participants commented frequently on the eroticism involved in exchanging power during BDSM sessions. They all expressed that experimenting with the exchange of power is a fundamental feature of a BDSM experience, and it is this shift in status, either to the dominant or submissive position, that is key to successful BDSM play for these participants. 
The submissive and dominant partners locate eroticism differently within the same sexual scene, and much of what is considered to be erotic is related to the assumed sexual role.

\section{Eroticism in submission}

Among the submissive partners there appeared to be many commonalities in the understanding expressed by the participants who adopted this sexual role, with the process of demotion to the lower, submissive status having a central influence on their erotic enjoyment of the session. The elevated power and status attained by the dominant partner was a constant source of arousal for the submissive participants. The implicit knowledge that the dominant partner possessed such power was erotic for them, and this implicit knowledge, which preceded any sexual acts, was a major constituent of the erotic experience. The submissive participants reported being in awe of the power enjoyed by the dominant partner, and their authority to control and direct the sexual situation. The very fact that the dominant partner could do this as a direct result of their own submission, was another erotic element reported by the submissive participants, it highlighted their own lack of power and status, as illustrated in the following excerpt:

Interviewer: Can you tell me about these feelings of humiliation?

Annie: (pause) It's...it enforces my position as belonging to him, that he can treat me that way and I don't have any comeback. I wonder...wonder whether part of it is to do with the feeling of being so very vulnerable. It places you in a vulnerable position, and accentuates the feeling of vulnerability. It's evidence of Robert's power though that I think is what I find most...erotic, and evidence of my submission. [...] it's about feeling vulnerable and exposed and knowing how to play with that just enough so it feels sexy... 
Submissive participants' powerlessness was framed as a multi-faceted erotic experience, consisting of both the psychological act of submission, and the physical and psychological consequences of this action. In terms of the act of submission, all submissive participants mentioned the removal of responsibility as a particularly erotic aspect of submission. The notion of not having to make choices or take decisions was particularly appealing, and participants described this lack of responsibility as a pleasurable contribution to the sexual experience.

It does feel like you're free. You don't have to behave in the conventional way because all the rules are different. I could just be totally selfish and enjoy this amazing sex. I didn't have to try to please my partner; I was pleasing him by letting him use me how he wanted. I could just bask in the experience of it all. I was under his control completely, I didn't have to think or do anything but let him use me, and I had no idea what might happen to me. (Patrick)

The act of submission also removes practitioners' autonomy, which grants all control to the dominant partner. It is the dominant partner who orchestrates the theme and content of the scene, including the sexual practices that occur. The submissive partners have no autonomy to question the dominants' choices, because the characteristics of the role eliminate their independence and surrender it to the dominant partner during the power exchange. Contributing another erotic aspect to the submissive experience is the abolition of the notion of free will within the BDSM context. As the UK is a relatively liberal country, this appears on the surface, to be an incongruous concept from which to derive sexual pleasure; however, it is only erotic within the fantasy of the power exchange. In the context of the BDSM scene, 
submissive partners must obey dominant partners and submit to their power, and the removal of free will in this context only is an erotic experience for the participants. Allowing this to happen during BDSM leads participants to attest to wonderful, unexpected sexual experiences, as submissive partners are unable to refuse the dominant's wishes and are therefore able to engage in sexual practises they would otherwise be inhibited against. This must occur, of course, within the realms of fantasy and consent.

Another erotic aspect derived from the submissives' experience of powerlessness is the complex way that contrary emotions are synthesised to contribute to the erotic experience. Submissive partners frequently discussed the range of conflicting and contrary emotions experienced when submitting during BDSM. Emotions that are conventionally considered incompatible and that are not usually experienced together can become synthesised during BDSM and are converted into something erotic for the participants. In the excerpt below, Annie described how the combination of feelings of humiliation and enjoyment became arousing for her and enhanced her sexual experience within the scene.

I felt rejected by Robert, which heightened my feelings of humiliation and asserted his power. It emphasised he has the power to do this, to bring another slave in [to the scene] if he wanted to, and the fact he had all this power was sexy and that's where the paradox arises. I absolutely hated having Sue join us under those conditions, but really got off on Robert exercising his power muscles. I was aroused as well as feeling like dirt, it's a strange combination of feelings, but BDSM does allow me to feel paradoxical things and that's why it's so fulfilling and so exciting. It's a...fusion of sensations and emotions, and in this case it was humiliation, jealousy and sexual arousal. 
The erotic unknown was a major aspect of the erotic experience for all of the submissive participants interviewed and it refers to the sexual excitement arising from uncertainty about what is going to happen. This erotic element was more salient for the submissive partners as opposed to the dominant partners, though imposing this erotic unknown onto submissives was interpreted as erotic by some of the dominant participants. It was felt that there should be some element of the unexpected involved in the submissives' BDSM experience as this fuels the eroticism of the sexual scene. The submissive partners framed this as fundamental to their erotic excitement, and reported that they achieved a more enjoyable scene when they were completely unaware of what was going to happen to them. This held more eroticism than if they were consulted or were aware of the detail of the fantasy, as detailed in the following quote from Patrick:

I had no idea who would be doing what to me, and that was really horny. They could really hurt me or really abuse me, do whatever they wanted and I'd have no choice in it. I wouldn't be consulted. I would just be there to be used by them however they wanted, I couldn't object and that was a massive turn on. [....] I enjoy feeling like anything could happen...

This sense of anticipation featured prominently throughout the participant interviews, and was expressed in various experiential facets.

Anticipating the sexual scene was a common erotic element among the submissive partners, where they would imagine all the potential possibilities that the dominant partner had in store for them. This often occurred when participants were restrained or blindfolded, and they felt particularly powerless to influence the scene. This was framed as erotic by many of the participants as it enhanced feelings of fear and vulnerability, and emphasised their own 
position of powerlessness and helplessness. Anticipation was also framed by many submissive participants as a kind of foreplay, whereby the anticipation and excitement of what is to follow is sexually arousing.

I was quite afraid really, of what was to come. It's always the anticipating when you do BDSM, waiting to see what's going happen to you, imagining all the possibilities, it's very exciting! It was a bit like waiting for the big drop on a rollercoaster, I didn't want it to happen, but I had got on and I couldn't stop it so the best thing was just to try and let myself go and embrace the big drop that was to come. (Lucy)

Lucy's quote illustrates the way anticipation can be viewed in terms of foreplay, and how this increases her sense of excitement.

\section{Eroticism in domination}

The eroticism derived during domination has fewer strata than its submissive counterpart, although it is positioned as a significant sexual experience for dominant participants. Dominant partners described the sense of their all-powerful status as a main feature of their erotic experience. The eroticism arises from the awareness that they have ultimate power, status and total control, of both the sexual situation and of the submissive partner. This is reflective of the submissives' intense feelings of lack of power and control. Simply acknowledging this status shift is arousing, but also exercising this elevated status by dictating and directing the submissive partner and the sexual scene is sexually exciting, as demonstrated by the following excerpt: 
I find the feeling of power so overwhelmingly erotic and sexy and arousing. It's the feeling of holding another person's fate in your hands, and knowing that person will abide by your power, and respect that power enough to let you completely control them. It's such a rush, and that's why I could never switch, because I couldn't do without that rush of power I get from domination. [....] It lets me have that absolute power, and I feel totally in control... When I feel so in control, that's what I find erotic, that someone respects me to the nth degree, that they will give me total control over their life. (Kim)

This total control is paramount for all of the dominant participants interviewed and is a central feature of their overall erotic experience; the more intense the sense of control achieved, the better their sexual experience.

Another central element to erotically fulfilling domination is the attention and adulation bestowed upon them by the submissive partner. The submissives' desire to please them, along with a high level of respect from their submissive partner, forms part of the erotic experience. A prominent aspect of domination is that the dominant partners have absolute sexual choice during BDSM. They are the directors of the sexual scene, therefore they can decide on the scenes, themes and sexual acts involved, thereby ensuring their own sexual needs and desires are met. They are free to impose their sexual will upon the submissive partners, generating a fantasy of perceived unlimited sexual scope. In the same way that the submissive participants were pleased with not having to decide what to do sexually given the contextual removal of their independence, free will and responsibility, the dominant partners thrive on making the sexual decisions and controlling the sexual choices. This theme highlights the complexity and the contextually bound nature of eroticism with BDSM, and highlights the nuanced differences for those adopting dominant and submissive roles. 


\section{Co-creating the erotic fantasy}

Creating an erotic world of fantasy is fundamental to the eroticism of BDSM for these participants, and this includes the adoption of the erotic roles mentioned earlier. Within the experience of BDSM there is a clear and definite separation between the consensually created world of sexual fantasy and the world of 'real' life. The fantasy world provides context and an erotic lens through which to understand the sexual scene. Clearly defined boundaries are drawn, which, providing the two remain separate, can lead to successful BDSM. However, when the 'real world' and the 'fantasy worlds' begin to merge, or overlap, the BDSM can lose its eroticism. Reality appears as an intrusion on the scene, although 'behind the scene' some semblance of the 'real' world must feature discreetly in order to maintain a sense of safety and security. There is a clear difference between wanting to engage in a BDSM related sexual fantasy and wanting the same event to happen outside of that world of fantasy. Participants were clear that whatever they consider to be erotic within the context of BDSM, they would not find pleasurable in a non-BDSM, or 'real life' context. The co-created fantasy world allows certain activities and scenes to be interpreted as erotic within this context, but, would not be eroticised outside of that context. This is illustrated by the following excerpt:

Interviewer: You mentioned that you were 'unable to object, completely taken over'. Can you tell me more about how that felt?

Tom: It was quite scary, but then I wouldn't have allowed myself to be in that situation if I didn't trust Joe completely, although I couldn't see, I couldn't hear and I couldn't speak and I was tied down so I couldn't move, there was nothing I could have done. He could have killed me if he wanted. The fear amplifies the sensation, just the fact you're scared and having adrenaline in your system 
heightens the sexual experience, I think being scared in that situation amplifies things more than if you were just lying there being able to see. I think it's...a safe fear.

The responses to the non-erotic reality of certain practices and acts can range from mere indifference to fear, and this varies between participants and personal fantasies. It is the discrete awareness that the scene is part of the pretence of fantasy that enables it to become eroticised. For example, as detailed earlier, it is the submissives' awareness that they choose to give up choice that enables the creation of a bubble of fantasy. This was emphasised by all of the participants as a key component of the erotic experience. It is the pretence of danger; the danger that occurs within the fantasy play, which is erotic. Experiencing such danger in the 'real' world is not a sexually exciting prospect but a terrifying one, and the reality of danger loses all sense of eroticism. When participants experience problems engaging with the chosen fantasy, difficulties relating to the scene's eroticism arise, and threaten the bubble of fantasy. It is critical for erotic satisfaction that BDSM practitioners are able to immerse themselves in the alternative sexual reality created. When this proves difficult or impossible, it becomes problematic for the participants to really engage with the sexual scene.

One issue is if the fantasy is missing components that participants consider crucial; this can be a feature or concept that the participants' consider to be important during the fantasy, a particular prop or something else from the sexual scene. The feature may be absent or lost at any time from the creation stage through to sexual roles through to the sexual acts, and once this has gone the participants lose the sense of eroticism. Participants referred frequently to the need for believability and explainability of the fantasy; every aspect from costume to dialogue to props, must always make sense for the BDSM to work, 
Kim: It was important we each looked like we should if we were really a headmistress or a student, otherwise we might have been acting any fantasy. You need action as well as words when you're doing SM, and what you wear can have a big impact on the SM. [...]

Interviewer: Can you imagine if you were wearing plain clothing like you would usually wear...

Kim: There's no doubt that the clothes...facilitate the role play. I think it would be very difficult without dressing up. Why would a headmistress be wearing jumper and jeans? She would have to dress a certain way for work, so I would have to dress a certain way to play her role. [...] It doesn't make sense to go to the trouble of planning a fantasy and then not going through with it properly and incorporating clothes and things as well.

There may be various reasons why participants feel unable to immerse themselves in a particular fantasy, though often it is because they are constrained by a particular feature of the fantasy such as particular sounds, dialogue or smells for example. These features may appear clumsy, ill-considered, disingenuous or unrealistic and as a result participants fail to immerse themselves satisfactorily in the fantasy, and so the eroticism is lost.

He was supposed to be the dominant partner, he wasn't supposed to consult with me about what I wanted. That's the worst thing someone can do because then I feel as though they have no power, where is their power if they have to ask? $\mathrm{He}$ should do what he wanted to do, what he enjoyed, not ask me how I like it! I'm supposed to be subservient to him, not have opinions about types of bondage. It's 
not arousing when I had an expectation that I was going to be dominated by a sadist, and the first thing is I'm asked what I prefer to do. (Maria)

These excerpts referring to unsuccessful experiences illustrate that many things can burst the bubble of fantasy that is necessary for erotic BDSM. An unrealistic sexual scene can upset the maintenance of the fantasy, as although all involved are aware on some level that the play is fantasy, this knowledge must be suspended or it will threaten the success of the erotic fantasy.

\section{Discussion}

The findings highlight the crucial importance of the co-created nature of the fantasy involved in the erotic experience of BDSM that enables the suspension of disbelief and a deep immersion into the bubble of the erotic fantasy, which is collaboratively maintained by dominant and submissive partners working together. In earlier work, Turley, Monro and King (2017) suggests that a purpose of fantasy within BDSM is to create a contextual field that transforms unpleasant acts into sexually pleasurable activities; therefore, the fantasies contextualise the BDSM experience. The research presented in this paper extends these analyses by arguing that it is the co-created nature of the architecture of the fantasy and adopted sexual roles that not only contextualise the BDSM, but is also a key erotic constituent of the sexual experience. Here our findings align with Weinberg's (1978) early speculation that BDSM should be understood as a co-constructed performance, where BDSM occurs within a theatrical frame, one where apparent cruelty and/or violence are transformed into pleasurable play.

As fantasies serve to eroticise BDSM activities, all participants are aware of the contextual field within which their play occurs. Therefore, it is understood, for example, that 
the contextual field of rape is completely different from the contextual field of a rape scene during BDSM, and it is the fantasy that eroticises the scene. Weeks (1995) emphasises the subjectivity of BDSM; the meaning of the situation is understood and shared by the involved participants. Our findings illustrate how participants, through shared subjectivity, recognised that they were engaging in a mutual erotic fantasy, and this enables participants to become completely immersed and to suspend all knowledge of the reality existing outside of the world of fantasy. Engaging in BDSM enables the realisation of forbidden fantasies (Weeks, 1985), and the exploration of these fantasies in a safe, mutually constructed space.

Our findings also elucidated the collaborative, consensual nature of BDSM fantasy. There is an abundance of quantitative research examining the range of BDSM fantasy content along with data on prevalence and frequency of dominant/submissive fantasies (see Santtila, Sandnabba \& Nordling, 2001; Zurbriggen \& Yost, 2004), along with some useful qualitative work relating to BDSM and fantasy (see Rubin; 2005, Weiss, 2011; Lindemann, 2012). By taking a phenomenological psychological perspective, our experiential approach has provided much richer and 'thicker' descriptions about the eroticism of the lived experience of BDSM, offering more subtle and sophisticated insights and extending the existing literature. It emphasises the importance of the relational aspect of BDSM for these participants, and how, despite its appearance, the architecture of the scene is constructed collaboratively through the adoption of sexual roles satisfying the different erotic interests of those involved. The role dynamics during the BDSM play along with the sexual actions engaged in have a direct impact on the eroticism of those involved. The collaboratively produced erotic scene enables the immersion required in order to suspend the sense of the outside reality and adopt the alternative sexual reality constructed through fantasy play.

In terms of the utility and application of these findings, psychotherapists and others working in the mental health field may wish to consider incorporating depathologising 
approaches to erotic diversity into their practice. This could include encouraging clients to disclose an interest in BDSM by using terms such as 'erotic play', 'role play' and 'consent', to signify a willingness to hear about such practices, should they be relevant to the client.

\section{Limitations}

There were limits to diversity in the participant sample. All participants with the exception of one were white, all were cisgender, able bodied and all were under the age of fifty. The sampling strategies were designed to recruit a varied selection of participants, however, despite attempting to include transgender and genderqueer participants in the sample to increase diversity, this was unsuccessful. Clarke, Ellis, Peel and Riggs (2010) note that within the LGBTQ community some groups are more difficult to sample, including older people, non-white people, trans people, bisexual people and also individuals who engage in marginalised behaviour, such as consensual BDSM.

The size of the sample also bears mention here; a total of nine participants were recruited for this research, and although this appears to be a small sample, it is not unusual for phenomenological researchers to work with fewer participants than in other forms of qualitative research (Giorgi, 1997). It should be noted that the aim of phenomenological research is not be representative of the general BDSM population, but to examine the lived experiences of a small number of BDSM practitioners. We argue that the quality of the data and the work done to elucidate the detail is significant, rather than the number of participants employed.

The main limitation regarding the use of the snowball sampling strategy is the risk of a homogenous sample, and that by asking current participants to suggest participation to other people in their social circle, it can lead to the sample consisting of individuals who are similar to each other. It is likely that a homogenous sample of this nature will not reach those 
practitioners participating in BDSM on the fringes of the community. This risk was minimised in this research by snowballing the sample from more than one participant in order to reach individuals from different social circles.

\section{Conclusion}

The purpose of this study was to take an experiential approach to the investigation of the eroticism of BDSM. To date, we have discovered no other research conducted in this way on this topic, and this study therefore probably represents the first experiential analysis of the eroticism of BDSM participation published in English. In order to take an experiential approach to the work, an interpretive phenomenological stance was adopted, and the analytical method of template analysis was used because of its flexibility to tailor the analysis, and focus on particularly important and interesting thematic areas. The findings showed that the erotic constituents of BDSM manifested in an opposing but complimentary manner for dominant and submissive partners. The importance of context was particularly highlighted by the participants. The sexual practices and acts were only experienced as sexually pleasurable when occurring through the erotic lens, and would not be interpreted this way outside of the fantasy context. Taking an experiential approach to this study has provided a more subtle and nuanced insight into the erotic constituents of BDSM participation, and has examined in detail that which practitioners find erotic about these set of activities. It is clear however, that researchers need to work harder to reach unrepresented individuals and groups to ensure that their experiences are not omitted from sex research. The use of diverse methods in sex research can broaden the knowledge base of the topic, which is often dominated by neuropsychological studies. Taking an experiential approach to the current research has yielded fascinating findings and is worthy of consideration for use more broadly in sex research. 
Word count: 6667

\section{References}

Alison. L, Santtila. P, Sandnabba. N.K., \& Nordling. N. (2001). Sadomasochistically oriented behavior: Diversity in practice and meaning. Archives of Sexual Behavior, $30,1-12$

Ariel. S,. (2002). Children's Imaginative Play: A visit to Wonderland. Westport: CT Preager.

Barker, M., Iantaffi, A., \& Gupta, C. (2007). Kinky clients, kinky counselling? The challenges and potentials of BDSM. In L. Moon (Ed). Feeling Queer or Queer Feelings: Counselling and Sexual Cultures. (pp.106-124). London: Routledge.

Clarke, V., Ellis, S., Peel, E., \& Riggs, D. (2010). Lesbian, Gay, Bisexual, Trans \& Queer Psychology An Introduction. Cambridge: Cambridge University Press.

Connolly, P. (2006). Psychological functioning of bondage/domination/sado-masochism (BDSM) practitioners. Journal of Psychology and Human Sexuality, 18 (1), 79-120.

Denman, C. (2004). Sexuality: A Biosocial Approach. Basingstoke: Palgrave Macmillan. 
Ellard-Gray, A., Jeffrey, N.K., Choubak, M. \& Crann, S.E. (2015). Finding the hidden participant. Solutions for recruiting hidden, hard to reach, and vulnerable populations. International Journal of Qualitative Research, 14 (5), 1-10.

Faccio, E., Casini, C., \& Cipolletta, S. (2014). Forbidden games: the construction of sexuality and sexual pleasure by BDSM ;players'. Culture, Health \& Sexuality, 16 (7), 752-764.

Giorgi, A. (1997). The theory, practice and evaluation of the Phenomenological method as a qualitative research procedure. Journal of Phenomenological Psychology, 28, (2), 235-260.

Harviainen, J.T. (2011). Sadomasochist role-playing as live-action role-playing: A trait descriptive analysis. International Journal of Role Playing, 2, 59-70.

King, N. (2012). Doing template analysis. In C. Cassell \& G. Symon (Eds). Essential Guide to Qualitative Methods in Organisational Research (2nd ed) (pp. 453-478) London: Sage.

Kinsey, A., Pomeroy, W,C., Martin, C.E., \& Gebhard, P. (1953). Sexual behaviour in the Human Female. Philadelphia: Saunders.

Kleinplatz, P. \& Moser, C. (Eds). (2006). Sadomasochism: Powerful Pleasures. New York: Harrington Park Press.

Langdridge, D. (2007). Phenomenological Psychology Theory, Research and 
Method. Glasgow: Pearson Prentice Hall.

Langdridge, D. (2006). Voices from the margins: Sadomasochism and sexual citizenship. Citizenship Studies, 10 (4), 373-389.

Langdridge, D. \& Butt, T. (2005). The erotic construction of power exchange. Journal of Constructivist Psychology. 18 (1), 65-73.

Lindemann, D. (2012). Dominatrix: Gender, Eroticism and Control in the Dungeon. Chicago: Chicago University Press.

Moser, C. (1988). Sadomasochism. Journal of Social Work and Human Sexuality, 7, 43-56.

Moser, C. \& Kleinplatz, P. (2006). Introduction: The state of our knowledge on SM. Journal of Homosexuality, 2/3, 1-15.

Moustakas, C. (1994). Phenomenological Research Methods. London: Sage.

Nordling, N., Sandnabba, N.K., Santtila, P., \& Alison, L. (2006). Differences and similarities between gay and straight individuals involved in the sadomasochistic subculture. Journal of Homosexuality: Special Issue: Sadomasochism: Powerful Pleasures, 50 (2-3), 41-57. 
Richters, J., de Visser, R.O., Rissel, C.E., Grulich, A.E., \& Smith, A.M. (2008). Demographic and psychosocial features of participants in bondage and discipline, 'sadomasochism" or dominance and submission (BDSM): data from a national survey. The Journal of Sexual Medicine, 5(7), 1660-1668.

Rubin, G. (2005). The Catacombs: A Temple of the Butthole. In M. Thomson (Ed). Leatherfolk. Los Angeles: Daedalus Publishing.

Sandnabba, N.K., Santtila, P., \& Nordling, N. (1999). Sexual behaviour and social adaption among sadomasochistically-oriented males. Journal of Sex Research, 36, $273-282$.

Spinelli, E. (2005). The Interpreted World: An Introduction to Phenomenological Psychology. London: Sage.

Stockwell, F.M.J., Walker, D.J., \& Eshleman, J.W., (2010). Measures of implicit and explicit attitudes towards mainstream and BDSM sexual terms using the IRAP and questionnaire with BDSM/fetish and student participants. The Psychological Record, $60,307-324$.

Tomassilli. J, Golub, S., Bimbi, D. \& Parsons, J. (2009). Behind closed doors: An exploration of kinky sexual behaviors in urban lesbian and bisexual women. Journal of Sex Research, 46 (5), 438-445. 
Turley, E.L. (2018 in press). Leading and Following? Understanding the power dynamics in consensual BDSM. In Beggan, J. K., \& Allison, S. T. (Eds.). Leadership and sexuality: Power, principles, and processes. Northampton, MA: Edward Elgar.

Turley, E.L., Monro, S. \& King, N. (2017). Adventures of Pleasure: Conceptualising consensual bondage, discipline, dominance \& submission, and sadism \& masochism (BDSM) as a form of adult play. International Journal of Play, 6 (3), 324-334.

Turley, E.L. (2016). 'Like nothing I've ever felt before': understanding consensual BDSM as embodied experience. Psychology and Sexuality. 7(2), pp.149-162.

Turley, E.L. \& Butt, T. (2015). BDSM - bondage and discipline; dominance and submission; sadism and masochism. (pp.24-41). In C. Richards \& M.J. Barker (Eds). The Palgrave Handbook of the Psychology of Sexuality and Gender.

Turley, E.L., King, N. \& Butt, T. (2011). 'It started when I barked once when I was licking his boots!': a descriptive phenomenological study of the experience of BDSM. Psychology \& Sexuality, 2 (2), 123-136.

Weeks, J. (1985). Sexuality and its Discontents. London: Routledge \& Kegan Paul.

Weeks, J. (1995). Invented Moralities Sexual Values in Age of Uncertainty. Cambridge: Polity Press.

Weinberg, T.S. (1978) Sadism and masochism: Sociological perspectives. Bulletin 
of the AAPL, 6 (3), 284-295.

Weiss, M. (2006). Mainstreaming kink: The politics of BDSM representation in US popular media. Journal of Homosexuality, 2-3, 103-132.

Weiss, M. (2011). Techniques of Pleasure: BDSM and the Circuits of Sexuality. Durham, NC: Duke University Press.

Wismeijer, A. A. J., \& van Assen, M.A.L M. (2013). Psychological characteristics of BDSM practitioners. Journal of Sexual Medicine, 10(8), 1949-1952.

Wilkinson, E. (2009). Perverting visual pleasure: Representing sadomasochism. Sexualities, 12 (2), 181-198.

Willig, C. (2008). A phenomenological investigation of the experience of taking part in 'extreme' sports. Journal of Health Psychology, 13 (5), 690-702.

Yost, M. (2007). Sexual fantasies of S/M practitioners: The impact of gender and S/M role on fantasy content. In D. Langdridge \& M. Barker (Eds). Safe, Sane and Consensual Contemporary Perspectives on Sadomasochism (pp.135-154).

Basingstoke: Palgrave Macmillan.

Yost, M. (2009). Development and validation of the Attitudes about Sadomasochism Scale. Journal of Sex Research, 47 (1), 79-91. 
Zurbriggen, E.L., \& Yost, M. (2004). Power, desire \& pleasure in sexual fantasies. Journal of Sex Research, 41 (3), 288-300. 